\title{
Caregiver-reported health-related quality of life of children with cerebral palsy and their families and its association with gross motor function: A South Indian study
}

\author{
S. Surender, Vykuntaraju K. Gowda'1, K. S. Sanjay, G. V. Basavaraja, Naveen Benakappa, Asha Benakappa \\ Departments of Paediatrics and ${ }^{1}$ Paediatric Neurology, Indira Gandhi Institute of Child Health, Bengaluru, Karnataka, India
}

\begin{abstract}
Introduction: In children, health-related quality of life (HRQOL) includes parental impact and family functioning along with concepts of illness, functional status, mental health, and comfort. We are focusing on the impact of cerebral palsy (CP) on children's HRQOL and their families, and its relationship with gross motor dysfunction. Subjects and Methods: CP children aged 3-10 years under regular neurology follow-up were enrolled. The HRQOL and motor severity were prospectively assessed using lifestyle assessment questionnaire-CP and gross motor function classification systems, respectively. Results: One hundred children participated in this study. Thirty-three percent of children had good, $22 \%$ had mildly affected, whereas $45 \%$ had moderately to severely affected HRQOL. A significant association is present between gross motor function classification system and HRQOL. Conclusion: HRQOL in CP and their caregivers is highly impaired. The degree of impairment is associated with physical independence, mobility, clinical burden, and social integration dimensions. Therapies targeting these dimensions and associated comorbidities will improve the HRQOL. Gross motor function classification system is a good indicator of HRQOL.
\end{abstract}

Key words: Caregiver, cerebral palsy, gross motor function classification, health-related quality of life

\section{Introduction}

Cerebral palsy (CP) is a group of disorders which is permanent but not unchanging; it involves a disorder of movement and/or posture and of motor function; it is due to a nonprogressive interference/lesion/abnormality; this interference/lesion/abnormality is in the developing/ immature brain. ${ }^{[1]} \mathrm{CP}$ is a chronic motor disabling condition with a prevalence rate of 1.2-2.5/1000 school age children as per various studies, ${ }^{[2,3]}$ but there is no data specific to India. CP is often associated with epilepsy,

\section{Address for correspondence:}

Dr. Vykuntaraju K. Gowda, Bangalore Child Neurology and

Rehabilitation Center, HANS Complex, 8/A $1^{\text {st }}$ Main $1^{\text {st }}$ Cross,

Manuvana, Near Adichunchanagiri Choultry, Vijayanagar,

Bengaluru - 560 040, Karnataka, India.

E-mail: drknvraju@hotmail.com

\begin{tabular}{|l|l|}
\hline \multicolumn{2}{|c|}{ Access this article online } \\
\hline Quick Response Code: & Website: \\
\hline & www.ruralneuropractice.com \\
\cline { 2 - 3 } & \\
\hline
\end{tabular}

musculoskeletal problems, behavioral, sensorial, cognitive, and communicational disorders. ${ }^{[4,5]}$ All these various comorbidities have a serious negative impact on the lives of children with CP. ${ }^{[6,7]}$ They spend 2.2 times the amount of time in outpatients when compared with other normal peers, also requiring complex and integrated health care, ${ }^{[8,9]}$ thus reinstating the fact that the treatment and care of such children can be burdensome to parents thereby leading unstable family conditions and inability to cope with the problem. Therefore, quality of life (QOL) in children with $\mathrm{CP}$ is a tool for assessing the effectiveness of the treatment of $\mathrm{CP} \cdot{ }^{[10]}$

Health-related QOL (HRQOL) is considered a multidimensional construct that embraces several domains of physical and psychological well-being. ${ }^{[11,12]}$

This is an open access article distributed under the terms of the Creative Commons Attribution-NonCommercial-ShareAlike 3.0 License, which allows others to remix, tweak, and build upon the work non-commercially, as long as the author is credited and the new creations are licensed under the identical terms.

For reprints contact: reprints@medknow.com

How to cite this article: Surender S, Gowda VK, Sanjay KS, Basavaraja GV, Benakappa N, Benakappa A. Caregiver-reported health-related quality of life of children with cerebral palsy and their families and its association with gross motor function: A South Indian study. J Neurosci Rural Pract 2016;7:223-7. 
In children, HRQOL includes parental impact and family functioning along with the concepts of illness, functional status, mental health, and comfort. ${ }^{[13]}$ Self-reporting is said to be the gold standard for HRQOL assessment in pediatric population, but it may be difficult to obtain reliable information from children with severe intellectual impairments or significant communication problems as in children with CP. ${ }^{[14]}$ In this sense, some authors have suggested the possibility to assess children's HRQOL by using reports from proxies (parents, health, and teachers). ${ }^{[15,16]}$ Indeed, several studies have used parent's reports to assess HRQOL in pediatric population with CP. ${ }^{[13,14]}$ There are various types of disease-specific and generic measures available for assessment of HRQOL. Disease-specific tool would be more appropriate in measuring the morbidity.

Lifestyle assessment questionnaire-CP (LAQ-CP) is a disease-specific caregiver (proxy) questionnaire developed for evaluating the impact of disability in children with CP and their families. Mackie et al. developed this questionnaire to assess the impact of impairment and disability on children with CP and on their families. This questionnaire is considered to be a reliable tool in measuring the QOL experienced by children with $C P$ in North England. ${ }^{[17]}$ Studies on HRQOL in children are scarce, and studies on CP children are even scarce in India. This study not only gives a picture of $\mathrm{CP}$ children in India, but also tells about the quality of health care provided to them.

\section{Aims}

To determine the health-related quality of life of children with cerebral palsy and their families and its correlation with gross motor function.

\section{Subjects and Methods}

\section{Methods \\ Study setting}

This study was conducted at a pediatric neurology outpatient clinic in a tertiary care center located in Bengaluru, India. The Paediatric Neurology department acts in unison with Neuro Development Clinic in the same Institute, which has a group of developmental pediatricians, clinical psychologists, special educators, speech therapists, and occupational therapists, and provides comprehensive care to children with developmental disabilities thereby working toward betterment and improving the QOL of a physically challenged child.

Children aged between 3 and 10 years who were diagnosed to be $\mathrm{CP}$ and under regular neurology follow-up along with regular physical therapy/occupational therapy received for last 1 year were included in the study. Absence of the primary caregiver, presence of other chronic illnesses not typically associated with $\mathrm{CP}$, for example, cystic fibrosis, congenital heart disease, chronic diarrhea, etc., and families having another child with $\mathrm{CP}$, autism, or mental retardation were excluded.

\section{Instruments and tools utilized Lifestyle assessment questionnaire-cerebral palsy}

The LAQ-CP is a 46-item questionnaire, classified into six dimensions: Physical independence, mobility, clinical burden, schooling, economic burden, and social integration. The impact of the child's problems on the family emerges as an important issue. Some of the questions in the questionnaire were modified to suit local context. Each response to the items in the questionnaire is scored from 0 to 4 using a scoring system as described in the LAQ-CP manual. Conversion of these raw scores into a final standard score, known as Lifestyle Assessment Score (LAS), is detailed in the manual. ${ }^{[18]}$ The LAS is expressed as a percentage score out of 100. A maximally disadvantaged/physically challenged child scores $100 \%$. The QOL is classified according to the LAS score as good $(<30 \%)$; mildly affected (30-50\%); moderately affected $(51-70 \%)$; and severely affected $(>70 \%)$.

\section{Gross motor functional classification system}

The Gross Motor Function Classification System (GMFCS $)^{[19]}$ was developed in response to the need to have a standardized system. This system helps in classifying and assessing the severity of child's motor disability into one of the five ordered levels with level I indicating the highest motor function independence and level $\mathrm{V}$ the lowest gross motor function. The GMFCS for CP is based on self-initiated movement, with emphasis on sitting, transfers, and mobility. GMFCS helps to predict gross motor development as most children will remain at the same level from age 2 to 12 years. ${ }^{[20]}$

\section{Sample size and statistical analysis of data}

As per previous studies' mean LAS, ${ }^{[21,22]}$ required sample size was 71. In this study, we enrolled 100 children. Data entered into excel sheet were statistically analyzed. Pearson correlation coefficient and ANOVA were used for analysis of data.

\section{Study procedure}

Children attending the Paediatric Neurology Clinic were screened for inclusion in the study. An informed consent was obtained from the parents after explaining the objective of the study. Confidentiality of information was assured. A detailed history including that of the therapy 
being received by the child and sociodemographic characteristics were obtained and entered in a predesigned proforma. After detailed neurological examination, the children were classified into spastic, ataxic, and dyskinetic as per the Surveillance of $\mathrm{CP}$ in Europe classification of CP. The children were also evaluated for comorbid condition associated with $\mathrm{CP}$ such as seizures, hearing or vision impairments, cognitive deficits, feeding problems, contractures, and behavioral problems. The etiology of $\mathrm{CP}$ was determined as per the history, previous records, and investigations.

The severity of motor disability was assessed and classified as per GMFCS. A personal interview of the primary caregiver of the child with $\mathrm{CP}$ was conducted in a distraction-free environment. The LAS was calculated as per the LAQ-CP manual. The scores were statistically analyzed. LAS and its various domains were also statistically analyzed for their correlation with GMFCS.

\section{Results}

One hundred children participated in this study as per the inclusion criteria, out of which boys were 61 and girls were 39 with male: female ratio of 1.5:1. The mean age group being 4.8 years. Bilateral spastic CP cases were predominant $69(69 \%)$, followed by unilateral CP $26(26 \%)$, and dyskinetic CP 5 (5\%). Severity of motor dysfunction based on GMFCS are as follows: Level I - 17 (17\%), II - 28 (28\%), III - 19 (19\%), IV - 13 (13\%), and V - 23 (23\%). Other demographic, birth, etiological, and nutritional characteristics and associated comorbidities are mentioned in Table 1.

Mean LAS score was 45.107 (95\% confidence interval 40.85-49.36). Thirty-three (33\%) children had good LAS, 22 (22\%) had mildly affected LAS, $24(24 \%)$ had moderately affected LAS, and 31 (31\%) had severely affected LAS.

Children with dyskinetic and bilateral spastic CP had higher LAS score when compared with children with unilateral spastic CP. Mean LAS scores in male and female children were almost same. Children with comorbidities such seizures, deformities, and behavioral problems had higher LAS scores. A significant association is present between GMFCS and LAS scores [Table 2]. There is a significant correlation between GMFCS and physical independence, mobility, clinical burden, and social integration dimensions. LAS scores have a positive correlation with physical independence, mobility, clinical burden, and social integration dimensions, and have no association with age and sex of child.
Table 1: Demographic characters

\begin{tabular}{|c|c|}
\hline Characteristics & Values \\
\hline Total number of cases & 100 \\
\hline \multicolumn{2}{|l|}{ Age (years) } \\
\hline Mean (SD) & $4.86(1.86)$ \\
\hline Median & 4 \\
\hline Cl 95\% & $4.5-5.23$ \\
\hline \multicolumn{2}{|l|}{ Sex } \\
\hline Male & 61 \\
\hline Female & 39 \\
\hline Ratio & $1.56: 1$ \\
\hline \multicolumn{2}{|c|}{ Cerebral palsy type as per SCPE classification } \\
\hline Spastic & 95 \\
\hline Unilateral & 26 \\
\hline Bilateral & 69 \\
\hline Dyskinetic & 5 \\
\hline Choreoathetoid CP & 3 \\
\hline Dystonic & 2 \\
\hline Ataxia & 0 \\
\hline Nonclassifiable & 0 \\
\hline \multicolumn{2}{|l|}{ GMFCS levels } \\
\hline I & 17 \\
\hline II & 28 \\
\hline III & 19 \\
\hline IV & 13 \\
\hline $\mathrm{V}$ & 23 \\
\hline \multicolumn{2}{|l|}{ Birth weight } \\
\hline Mean (SD) & $2.45(0.59)$ \\
\hline Median & 2.5 \\
\hline Microcephaly & 70 \\
\hline \multicolumn{2}{|l|}{ Protein energy malnutrition (as per IAP) } \\
\hline Grade 1 & 16 \\
\hline Grade 2 & 43 \\
\hline Grade 3 & 28 \\
\hline Grade 4 & 4 \\
\hline \multicolumn{2}{|l|}{ Comorbidities } \\
\hline Seizures & 60 \\
\hline Generalized tonic-clonic seizures & 31 \\
\hline Complex partial seizures & 19 \\
\hline West syndrome & 4 \\
\hline Myoclonic epilepsy & 1 \\
\hline Attention deficit hyperactive disorder & 6 \\
\hline Autism & 2 \\
\hline \multicolumn{2}{|l|}{ Deformities } \\
\hline Scoliosis & 1 \\
\hline Contracture & 7 \\
\hline Equinus & 1 \\
\hline \multicolumn{2}{|l|}{ Probable etiology } \\
\hline Hypoxia ischemic encephalopathy & 58 \\
\hline Preterm sequelae & 20 \\
\hline Postmeningitis sequelae & 6 \\
\hline Intracranial hemorrhage & 1 \\
\hline Perinatal stroke & 3 \\
\hline Neonatal sepsis & 4 \\
\hline Neonatal hypoglycemia & 3 \\
\hline Unknown & 5 \\
\hline
\end{tabular}


Table 2: Statistical analyses of lifestyle assessment questionnaire-cerebral palsy results

\begin{tabular}{|c|c|}
\hline Variables & Values \\
\hline \multicolumn{2}{|l|}{ LAS } \\
\hline Mean $(95 \% \mathrm{Cl})$ & $45.107(40.85-49.36)$ \\
\hline Median (SD) & $47.07(21.76)$ \\
\hline Good QOL (LAS <30\%) & $33(33)$ \\
\hline Mildly affected QOL (LAS 30-50\%) & $22(22)$ \\
\hline Moderately affected QOL (LAS 51-70\%) & $24(24)$ \\
\hline Severely affected QOL (LAS>70\%) & $21(21)$ \\
\hline \multicolumn{2}{|l|}{ Mean LAS scores } \\
\hline Males & 44.58 \\
\hline Females & 45.292 \\
\hline Unilateral spastic CP & 23.69 \\
\hline Bilateral spastic CP & 51.5 \\
\hline Dyskinetic spastic CP & 67.9 \\
\hline \multicolumn{2}{|l|}{ Mean dimensional scores } \\
\hline Physical independence & 44.5 \\
\hline Mobility & 53.71 \\
\hline Clinical burden & 22.31 \\
\hline Schooling & 1.37 \\
\hline Economic burden & 5.33 \\
\hline Social integration & 42.25 \\
\hline \multicolumn{2}{|l|}{ Correlation coefficient } \\
\hline \multicolumn{2}{|l|}{ GMFCS-LAS } \\
\hline GMFCS-physical independence & $0.897(P<0.001)$ \\
\hline GMFCS-mobility & $0.877(P<0.001)$ \\
\hline GMFCS-clinical burden & $0.852(P<0.001)$ \\
\hline GMFCS-schooling & $0.547(P<0.001)$ \\
\hline GMFCS-economic burden & -0.067 \\
\hline GMFCS-social integration & 0.215 \\
\hline Age-LAS & $0.658(P<0.001)$ \\
\hline Physical independence-LAS & 0.0038 \\
\hline Mobility-LAS & $0.970(P<0.001)$ \\
\hline Clinical burden-LAS & $0.951(P<0.001)$ \\
\hline Schooling-LAS & $0.541(P<0.001)$ \\
\hline Economic burden-LAS & -0.162 \\
\hline Social integration-LAS & 0.175 \\
\hline
\end{tabular}

QOL: Quality of life, LAS: Lifestyle assessment score, CP: Cerebral palsy, GMFCS: Gross motor function classifications system, SD: Standard deviation, Cl: Confidence interval

\section{Discussion}

This study evaluates the HQROL of CP children and their families and also analyzes its relationship with severity of motor dysfunction based on GMFCS levels. This study infers that $33 \%$ of children had good HRQOL and $22 \%$ had mildly affected HRQOL, whereas $45 \%$ had moderately to severely affected HRQOL. The mean LAS score was 45.07. An Indian study by Dobhal et al..$^{[21]}$ using similar questionnaire had a mean LAS of 56.6 and two-thirds of the children were moderately-severely affected which is high when compared with our study, probably the children enrolled in that study had higher GMFCS levels or did not get better delivery of health services. A Malaysian study by Lim and Wong ${ }^{[22]}$ using the same questionnaire but applied on small sample, had mean LAS of 44.89 which is similar to that our study, just reiterating a point that all developing nations have similar health delivery systems in place.

There is a clear association of GMFCS with LAS, which actually measures HRQOL. This fact that severity has a negative impact on HRQOL is also supported by other studies, ${ }^{[22-25]}$ but a Nigerian study by Tella et al..$^{[26]}$ differs stating that the children adapt to their decreased HQROL from beginning as they do not experience better QOL later in life. GMFCS levels have every strong correlation with physical independence, mobility, clinical burden, and social integration dimensions. Physical independence, mobility, clinical burden, and social integration dimension have negative impact on HRQOL of CP child. Many previous studies ${ }^{[21,22]}$ have similar opinion.

The economic burden impact on HRQOL was not significant, same as in Dobhal et al., for most services delivered were either free or subsidized. Unlike Dobhal et al., where the clinical burden on HRQOL was not significant, in our study the clinical burden had a significant influence on HRQOL as the hospital stay was more in severely affected children for they were subjected to surgeries (if needed), therapies and other rehabilitative measures, and it also contributed to increased parental stress.

Schooling impact on HRQOL was minimal as most children enrolled where aged below 5 years and attended preschool facilities near home and severely physically challenged children stayed at home. Social impact of CP on their HRQOL is the most important factor, as social implications on a CP child are enormous. There is undue stress on family in care, upbringing of a $\mathrm{CP}$ child. Parents of $\mathrm{CP}$ child require frequent health care facilities more often than other peers' parents. Moreover, there is some sort of restriction of social life in such parents. This is evident in our study also.

There is no significant association between LAS and age/sex of the $\mathrm{CP}$ child, this finding is consistent with other studies. ${ }^{[21,22]}$ However, children with comorbidities such as seizure, deformities, visual and hearing impairment, behavioral disorders such as attention deficit hyperactive disorder and autism have poor HQROL, which is also evidenced in other studies. ${ }^{[21,22,24]}$

Children with dyskinetic and bilateral spastic CP had poorer HRQOL when compared with unilateral spastic 
$\mathrm{CP}$, probably due to severity of motor impairment in the associated dyskinetic and bilateral spastic CP. Therapies targeting the improvement of dimensions such as physical independence, mobility, and social integration will definitely improve the HRQOL in CP children.

\section{Limitations}

Although we have used disease-specific questionnaire, certain domains have not been addressed as this questionnaire considers family participation. This questionnaire is only applicable to children aged between 3 and 10 years, so population below 3 years and above 10 years is missed. This can have some sort of implication on the study as the HRQOL might be poor in children $<3$ years, as clinical burden and social integration dimensions may be affected and more involved as parents' stress level is more and the child may subjected to early interventions such as surgeries and therapies.

\section{Conclusion}

HRQOL in CP and their caregivers is highly impaired. The degree of impairment is associated with physical independence, mobility, clinical burden, and social integration dimensions. Therapies targeting these domains may improve the HRQOL in these children. GMFCS is a good indicator of HRQOL in CP children. Many more studies should be undertaken for better understanding of QOL in CP children and for improving the same.

\section{Financial support and sponsorship}

Nil.

\section{Conflicts of interest}

There are no conflicts of interest.

\section{References}

1. Surveillance of Cerebral Palsy in Europe. Surveillance of cerebral palsy in Europe: A collaboration of cerebral palsy surveys and registers. Surveillance of Cerebral Palsy in Europe (SCPE). Dev Med Child Neurol 2000;42:816-24.

2. Pharoah PO, Platt MJ, Cooke T. The changing epidemiology of cerebral palsy. Arch Dis Child Fetal Neonatal Ed 1996;75:F169-73.

3. Hagberg B, Hagberg G, Olow I. The changing panorama of cerebral palsy in Sweden. VI. Prevalence and origin during the birth year period 1983-1986. Acta Paediatr 1993;82:387-93.

4. Bax M, Goldstein M, Rosenbaum P, Leviton A, Paneth N, Dan B, et al. Proposed definition and classification of cerebral palsy, April 2005. Dev Med Child Neurol 2005;47:571-6.

5. Rosenbaum P, Paneth N, Leviton A, Goldstein M, Bax M, Damiano D, et al. A report: The definition and classification of cerebral palsy April
2006. Dev Med Child Neurol Suppl 2007;109:8-14.

6. Engel JM, Petrina TJ, Dudgeon BJ, McKearnan KA. Cerebral palsy and chronic pain: A descriptive study of children and adolescents. Phys Occup Ther Pediatr 2005;25:73-84.

7. Parkinson KN, Gibson L, Dickinson HO, Colver AF. Pain in children with cerebral palsy: A cross-sectional multicentre European study. Acta Paediatr 2010;99:446-51.

8. Young D, Furler J, Vale M, Walker C, Segal L, Dunning P, et al. Patient engagement and coaching for health: The PEACH study - A cluster randomised controlled trial using the telephone to coach people with type 2 diabetes to engage with their GPs to improve diabetes care: A study protocol. BMC Fam Pract 2007;8:20.

9. Papavasiliou AS. Management of motor problems in cerebral palsy: A critical update for the clinician. Eur J Paediatr Neurol 2009;13:387-96.

10. Viehweger E, Robitail S, Rohon MA, Jacquemier M, Jouve JL, Bollini G, et al. Measuring quality of life in cerebral palsy children. Ann Readapt Med Phys 2008;51:119-37.

11. Bjornson KF, Belza B, Kartin D, Logsdon R, McLaughlin J, Thompson EA. The relationship of physical activity to health status and quality of life in cerebral palsy. Pediatr Phys Ther 2008;20:247-53.

12. Dickinson HO, Parkinson KN, Ravens-Sieberer U, Schirripa G, Thyen U, Arnaud C, et al. Self-reported quality of life of 8-12-year-old children with cerebral palsy: A cross-sectional European study. Lancet 2007;369:2171-8.

13. Beckung E, White-Koning M, Marcelli M, McManus V, Michelsen S, Parkes J, et al. Health status of children with cerebral palsy living in Europe: A multi-centre study. Child Care Health Dev 2008;34:806-14.

14. Arnaud C, White-Koning M, Michelsen SI, Parkes J, Parkinson K, Thyen U, et al. Parent-reported quality of life of children with cerebral palsy in Europe. Pediatrics 2008;121:54-64.

15. White-Koning M, Grandjean H, Colver A, Arnaud C. Parent and professional reports of the quality of life of children with cerebral palsy and associated intellectual impairment. Dev Med Child Neurol 2008;50:618-24.

16. Eiser C, Morse R. Can parents rate their child's health-related quality of life? Results of a systematic review. Qual Life Res 2001;10:347-57.

17. Mackie PC, Jessen EC, Jarvis SN. The lifestyle assessment questionnaire: An instrument to measure the impact of disability on the lives of children with cerebral palsy and their families. Child Care Health Dev 1998;24:473-86.

18. Mackie PC, Jessen EC, Jarvis SN. The Lifestyle Assessment Questionnaire (LAQ-CP) Manual. Newcastle upon Tyne: North of England Collaborative Cerebral Palsy Survey; 1998.

19. Palisano RJ, Hanna SE, Rosenbaum PL, Russell DJ, Walter SD, Wood EP, et al. Validation of a model of gross motor function for children with cerebral palsy. Phys Ther 2000;80:974-85.

20. Carnahan KD, Arner M, Hägglund G. Association between gross motor function (GMFCS) and manual ability (MACS) in children with cerebral palsy. A population-based study of 359 children. BMC Musculoskelet Disord 2007;8:50.

21. Dobhal M, Juneja M, Jain R, Sairam S, Thiagarajan D. Health-related quality of life in children with cerebral palsy and their families. Indian Pediatr 2014;51:385-7.

22. Lim MS, Wong CP. Impact of cerebral palsy on the quality of life in patients and their families. Neurol Asia 2009;14:27-33.

23. Puspitasari M, Rusmil K, Gurnida D. The relationship between gross motor function and quality of life among children with cerebral palsy. Disabil, CBR Incl Dev 2013;24:57-68.

24. Tessier DW, Hefner JL, Newmeyer A. Factors related to psychosocial quality of life for children with cerebral palsy. Int J Pediatr 2014;2014:204386.

25. Wake M, Salmon L, Reddihough D. Health status of Australian children with mild to severe cerebral palsy: Cross-sectional survey using the child health questionnaire. Dev Med Child Neurol 2003;45:194-9.

26. Tella BA, Gbiri CA, Osho OA, Ogunrinu AE. Health-related quality of life of Nigerian children with cerebral palsy. Disabil, CBR Incl Dev 2011;22:95-104 